\title{
YLIOPISTON MAATALOUSKIRJASTON UUSHANKINNAT v. 1945
}

\section{Maatalouden yleisteokset ja historia.}

A a 1 to ne n, V. T., Tieteellinen tutkimustyö. Opastusta aloitteleville luonnontutkijoille. Porvoo 1945. $269 \mathrm{~s}$.

A g ro-Forst 25 år. Hfors 1945. 13 s.

Boss, A., Wilson, H. K., \& Petersen, W. E., American farming. Agriculture. I. St Paul, Minn. 1939. 526 s

Det moderna Dan mark. Under red. av Hakon Stangerup. Övers. Sthlm 1942. $402 \mathrm{~s}$.

Ekstrand, $\AA$ ke, Allmänna lagar och förordningar rörande jorbruket. I-II. Sthlm 1937. $387 \mathrm{~s}$.

E r i x o n, Si g u rd, Svenska kulturgränser och kulturprovinser. Sthlm 1945. $66 \mathrm{~s}$. (K. Gustav Adolfs akademiens småskrifter. 1.)

H a a t a ja, Kyösti, Maa- ja vèsioikeus sekä metsä- ja maatalouslainsäädäntö. Porvoo 1945. 274 s.

H a l o n e n, A n t ti, Jättiläiset elävät yhä. Näköaloja Suuresta Lännestä. Hki 1945. $119 \mathrm{~s}$.

J o r d bruksproble m. Några aktuella föredrag. Sthlm 1943. 139 s.

Ka janto, Antero, Maa laulaa. Maahenkisiä tunnelma- ja lausuntarunoja. Hki 1945. $95 \mathrm{~s}$.

L a n d brugets Bierhverv. Haandbog for Landmæ.ld og Haveejere. Red. af O. Nielsen \& H. Mosegaard. Kbhvn 1944. $440 \mathrm{~s}$.

L a n t b r u ks - k a lender. Utg. av Lantbrukssällskapets tidskriftsaktiebolag. Arg. $30-31.1945-46$. Sthlm $1944-45.360+360 \mathrm{~s}$.

L a n t u n g d o m e n väljer yrke. Framtidsutsikter, utkomstmöjligheter och utbildningsvägar inom jordbrukets område. Handledning under red. av S. Örjangård, H. Röstin \& Anna-Lisa Lyberg. Sthlm 1944. $122 \mathrm{~s}$.

L i n d strö m, G. I., Kuvaus Euran pitäjästä. Suom. Hki 1944. 116 s.

M a a mi eh e n käsikirja. Toim. I. Poijärvi \& J. A. Wecksell. 2. pain. Hki 1945 $628 \mathrm{~s}$

M a a t a lo u d e n pikku jättiläinen. Toim. Seppo Simonen. 2. pain. Porvoo 1944 $1212 \mathrm{~s}$.

M a a t a 1 ouska le n teri. Toim. S. Mattsson \& A. J. Ollila. Vuosik. 34. 1945 Porvoo 1944. $301 \mathrm{~s}$.

M a a t a louskerhotyö ja maalaisnuorison kasvatus. Toim. Lounais-Suomen maatalouskerhopiiriliitto. Turku 1943. $64 \mathrm{~s}$. 
M i ch a i lov, N. N., Sovjetunionens geografi. Övers. Sthlm $1945.146 \mathrm{~s}$.

$\mathrm{Ni}$ in iva a ra, $\mathrm{H}$ u u g. Maatalousoppi kansakoulun jatkoluokkia varten. 13 pain. Hki 1944. $190 \mathrm{~s}$.

Norrla n d s bi bliog r a f i. Sthlm 1944. 64 s. (Industriens utredningsinstitut. Norrlandsutredningen.)

P a a sila h ti, S., Ryhtyisinkö maanviljelysinsinööriksi? Hki 1944. 12 s.

Pellervon kalenteri. Toim. V. Hannuksela. 1945. Hki 1944. $261 \mathrm{~s}$.

Planting, Birger, Baroner och patroner. Porträtt ur Sveriges jordbrukshistoria. 1700-talet. Sthlm 1944. $237 \mathrm{~s}$.

Porka la byg den och dess minnen. Under red. av E. Pontan \& A. Brenner. Hfors 1945. $341 \mathrm{~s}$.

R a n c ke n, A. W., Nynäsin säteri ja sen omistajat. Kouvola 1938. $15 \mathrm{~s}$.

Ra n toja, W., Ilmajoen maatalouskerho 20-vuotias. Seinäjoki 1945.11 s.

Rosenhane, Schering, Oeconomia. Utg. av. T. Lagerstedt. Uppsala 1944. $185 \mathrm{~s}$.

R y d b e r g, Sven A., Släktforskning. En vägledning. Sthlm 1944. $39 \mathrm{~s}$.

Rön n by, Erik, Sveriges natur och näringsliv. 2. uppl. Sthlm 1943. $162 \mathrm{~s}$.

S m e d s, H el mer, \& M a t tila, J or ma, Tuntematon Venäjä. Maa, kansa ja voimavarat. Hki 1945. $348 \mathrm{~s}$.

Suhonen, Em., Lyhyt maatalousoppi. 5. pain. Porvoo 1940. 130 s.

S ve n s s o n, Sig f r i d, Bondens år. Kalender och märkesdagar, hushållsregler och väderleksmärken. Sthlm [1945]. $191 \mathrm{~s}$.

T u o r l a h ti, V., Mustiala 1840-1940. Forssa 1943. $295 \mathrm{~s}$.

V e m var det? Biografier över bortgångna svenska män och kvinnor. Sthlm 1944. $357 \mathrm{~s}$.

A lenius, Nils, Hembygdsvården. Principer och arbetsmetoder. Sthlm 1940. 63 s. (Studentfören. Verdandis småskrifter. 425.)

Ö r j a n gå r d, Sig u r d, Duktigt folk. Sthlm 1945. $127 \mathrm{~s}$.

- - Lantungdomens klubbverksamhet. Sthlm 1945. $92 \mathrm{~s}$.

\section{Maa, maanviljelyskemia ja -fysiikka sekä lannoitus.}

A gerdyrkn ings 1 æ re. Lærebog for Landbrugsskolen. Udarb. af Karsten Iversen, H. Kryger Larsen, H. Land Jensen... 5. Udg. II. Gødningslæren. Odense 1942. 248 s.

Bolin, I., \& Gustaver, Bror, Kemi för gymnasiet. 4. uppl. Sthlm 1943. $349 \mathrm{~s}$

E h d o t u k s i a Suomen kemiallisen teollisuuden edistämistä tarkoittaviksi toimenpiteiksi. Komiteanmietintö. Hki 1944. 115 s. (Kemian keskusliiton julk. 4.)

G a u n itz, C. B., Hur man lägger komposter även med hänsyn till den bio-dynamiska metoden. Sthlm 1943. $68 \mathrm{~s}$.

Hu h t a 1 a, K a 11 e, Fysiikan oppikirja, 2. pain. I. Porvoo 1943. 463 s.

J o h a n s s o n, E m i l, Gödslingslära. Sthlm 1942. 178 s.

J o ha n s s o n, Si m o n, Om jord och vatten på Lanna försöksgård. Sthlm 1944. 41 s. (Sveriges geologiska undersökning. C. N. 461.)

J u u s e la. Ta neli, Einige Beobachtungen über das Messen der Bodentemperatur bei Anwendung von Thermoelementen. Hki 1945. Ss. 67-78. (Sonderdr.: Maataloustiet, aikakausk. 1945: 2.) 
Ke so, La uri, Maavesistä. Hki 1941. Ss. 173-190. (Erip.: Maataloustiet. aikakausk. 1941: 4.)

Kivin en, Erkki, Aluna- eli sulfaattimaista. Hki 1944. Ss. 147-161. (Erip.: Maataloustiet. aikakausk. 1944: 4.)

Sigmond, Alexius A. J. de, The principles of soil science. Transl. ed. by G. V. Jacks. London 1938. $362 \mathrm{~s}$.

[S ve d berg, The] The Svedberg $188430 / 8$ 1944. Uppsala 1944. 731 s.

T a lvitie, Arvi, Kemiallinen teknologia. I-II. Porvoo 1944-45. $580+646 \mathrm{~s}$.

Talvitie, Y., Kemiallisen teollisuutemme kotimaiset raaka-aineet. Hki 1945. 112 s. (Kemian keskusliiton julk. 6.)

- - - Tekoaineet. Hki 1945. 112 s. (Kemian keskusliiton julk. 9.)

Wills ta edt, Harry, \& Virgi n, E b b a, Kemi med biokemi. Sthlm 1942 $322 \mathrm{~s}$.

\section{Maanviljelystekniikka. Suo- ja laidunviljelys.}

A s s a r s s o n, G., Torrsubstanstillgång och vattenhalt i torvmarker i södra Sverige.

Sthlm 1944. $26 \mathrm{~s}$. (Sveriges geologiska undersökning. C. N. 462.)

Gelin d e r, C.-Fr., Lärobok i fältmätning och avvägning. Sthlm 1944. $57 \mathrm{~s}$.

Ju usela, T a n eli, Untersuchungen über den Einfluss des Entwässerungsverfahrens auf den Wassergehalt des Bodens, den Bodenfrost und die Bodentemperatur. (Diss.) Hki 1945. $212 \mathrm{~s}$.

Jän t ti, A u g., Pientalouksien laidunolot ja niiden parantaminen. Porvoo 1945. $89 \mathrm{~s}$.

$\longrightarrow$ - Suomen laidunolot. (Diss.) Hki 1945. $255 \mathrm{~s}$.

K e s o, L a u ri, Salaojituksen erikoisuuksista Suomessa. Forssa 1944. 8 s. (Erip.: Maatalous 1944: 4 .)

—- - Salaojituksen hoito. Hki 1944. 2 s. (Erip.: Maaseudun tulevaisuus 1944: 98.)

Larsson, Erik, Torvoljeundersökningar. Göteborg 1942. 23 s. (Chalmers tekniska högskolas handl. N. 13.)

Lukkala, O. J., \& Kotilainen, M. J., Soiden ojituskelpoisuus. 4. pain. Hki 1945. $56 \mathrm{~s}$.

Nilsso n, Th., Betesskötsel. 4. uppl. Sthlm 1943. $48 \mathrm{~s}$.

S u n d grén, A., \& Ekma n, E., Turve ja turpeen jalostus. Hki 1945. 24 s. (Kemian keskusliiton eripain. 29.)

$\mathrm{S}$ u u r o n e n, V., Kaskeaminen pellon ja laitumen perustamiskeinona. Hki 1945. 8 s.

S v e n ska jordbrukets bok. Torrläggning och bevattning Under red. av O. Fredholm. Sthlm 1941. $420 \mathrm{~s}$.

Vilenskij, D. G., Agregacija pošv, ee teorija i praktišeskoe priloženie. Leningrad 1945. $112 \mathrm{~s}$.

\section{Kasvinviljelys ja -jalostus.}

Frederiksen, Th., Kartoflen. 3. Udg. Kbhvn 1944. 267 s.

Fröla gen eller lagen angående handel med utsädesvaror. 3. uppl. utg. av H. Witte. Sthlm 1944. $48 \mathrm{~s}$.

Gericke, S., Voraussetzungen und Möglichkeiten einer Leistungssteigerung im deutschen Kartoffelbau unter besonderer Berücksichtigung der Düngung. Berlin 1943. $75 \mathrm{~s}$. 
Iversen, K., Oversigt over de for Landbruget vigtigste Resultater af Statens Forsøg i Plantekultur. 5. Udg. Kbhvn 1945. $188 \mathrm{~s}$.

J or tik ka, M., Kotimaisen tupakan viljeleminen ja valmistaminen. 5. pain. Porvoo $1945.69 \mathrm{~s}$.

K e e r s bu $1 \mathrm{ck}$, A. G. van, Handbok i linrötning med finesser i linberedning. Laholm 1945. $99 \mathrm{~s}$.

K i v i n e n, E., Kasvinviljelyksen yleiset edellytykset. Hki 1943. Ss. 5-27. (Erip.: Maamiehen käsikirja.)

Kretovič, V. L., Fiziologo-biochimičeskie osnovy chranenija zerna. Leningrad 1945. $136 \mathrm{~s}$.

Lunden, J. C., \& D u e, A., Forsøg med Bælgsæd. Kbhvn 1944. Ss. 603-633. (Beretn.fra Statens Forsøgsvirks. i Plantekultur 375.)

L ön n emark, H., Norska försök med olika sädesbärgningsmetoder. Uppsala 1944. 10 s. (Särtr. fr. Jordbrukstekn. föreningen, N. 57.)

Mosolov, V.P., Skvorcov, I. M., \& Čiževskij, M. G., Agrotechnika polevych kul'tur. Moskva 1945. $352 \mathrm{~s}$.

O sv a ld, H., Spånads- och oljeväxter. I. Spånadsväxter. II. Oljeväxter. Sthlm 1944-45. $259+223 \mathrm{~s}$.

Pes ola, V. A., Lisiä peltoherneen viljelysominaisuuksien tuntemiseen. Hki 1944. 4 s. (Ylip.: Maa 1944: 4.)

-i) - Neuvosto-Venäjän ja Suomen vuorovaikutus tieteen alalla. Kasvinjalostus. Hki 1945. Ss. 162-164. (Erip.: Valvoja 1945: 4.)

Perinnöllisyystiede ihmiskunnan palveluksessa. Hki 1944. 15 s. (Erip.: Kansanvalistusseuran kalenteri 1945.)

Saammeko Timantti-kevätvehnästä tänä kesänä tuleentuneen sadon? Hki 1944. 3 s. (Erip.: Maa 1944: 7-8.)

— - Tärkeimmät kevätvehnä-, ohra- ja kauralajikkeemme kenttäkokeiden valossa. Hki 1945. 4 s. (Ylip.: Maa 1945: 5.)

_-) Tärkeimmät kevätvehnälajikkeemme. Hki 1944. 4 s. (Erip.: Pellervo 1944: 8).

_- Vanhalla siemenellä vai uutisellako syysviljat kylvettävä? Forssa 1944. Ss. 35-38. (Erip.: Maatalous 1944: 2-3.)

Pohjakallio, O., Soijapavusta (Glycine hispida Max.) Hki 1945. Ss. 24-28. (Erip.: Luonnon ystävä 1945: 1.)

- Timotein jalostustyön tuloksista. Forssa 1944. Ss. 218-221. (Erip.: Maatalous 1944: 12.)

Über die Bedeutung der Hartschaligkeit des Samens als Sicherung des Rotkleebaues. Hki 1944. Ss. 115-126. (Sonderdr.: Maataloustiet. aikakausk. 1944: 3.)

—- Über einige ökologische Eigenschaften von Wiesenschwingelstämmen. Hki 1945. Ss. 33 - 43. (Sonderdr.: Maataloustiet. aikakausk. 1945: 2.)

- - Untersuchungen über die Resistenz von Hafer gegen die Trockenperiode. Hki 1944. Ss. 162-178. (Sonderdr.: Maataloustiet. aikakausk. 1944: 4.)

R a smussen, L., Korn. 2. Opl. Kbhvn 1944. 112 s.

$\longrightarrow$ - Roer. Kbhvn 1942. 81 s.

S a n d k le f, A 1 b., Lin och linne. Sthlm 1945. 53 s. (K. Gustav Adolfs akademiens småskrifter. 2.)

T a m m a n, A. I., Agrotechnika kartofelja. Moskva 1945. $40 \mathrm{~s}$.

To ble r, Fr., Sisal und andere Agavefasern. Berlin 1931. $104 \mathrm{~s}$. 
Va 11 e, Ot to, Öljykasvien viljelysmahdollisuuksista Suomessa. Hki 1945.8 s. (Ylip.: Työväen kalenteri 1945.)

\section{Kasvitaudit ja -tuholaiset.}

B ovie n, Pr., \& Th o m s e n, M., Haveplanternes Skadedyr og deres Bekœmpelse. Kbhvn 1945. $472 \mathrm{~s}$.

Ferdinandsen, C., \& Buch wald, N. F., Fysiogene Plantesygdomme. I-II. Kbhvn 1936. $149+214$ s.

Gram, Ernst, \& We ber, An n a, Plantesygdomme. 2. Opl. Kbhvn 1944. $558 \mathrm{~s}$.

I n g e ls t röm, E., Växtdoktorn. Handledning i kampen mot trädgårdens sjukdomar och skadedjur. Sthlm 1945. $253 \mathrm{~s}$.

L u n d bla d, K., Bristsjukdomar hos odlade växter. Sthlm 1945. 23 s.

Neerga ard, P., Danish species of Alternaria and Stemphyllium. Taxonomy, parasitism, economical significance. (Diss.) Copenhagen 1945. $560 \mathrm{~s}$.

Rostrup, Sofie, Vort Landbrugs Skadedyr. 5. rev. Udg. ved Pr. Bovien \& M. Thomsen. Kbhvn 1940. $400 \mathrm{~s}$.

T a lv it i e, Y. K. K., Kasvinsuojeluaineista ja niiden valmistusmahdollisuuksista Suomessa. Hki 1945. 39 s. (Kemian keskusliiton julk. 8.)

Tu $11 \mathrm{~g}$ r e n, A 1 b., Trädgårdens skadedjur. 2. uppl. Sthlm 1939. $246 \mathrm{~s}$.

Vogt, Ernst, Die chemischen Pflanzenschutzmittel. 2. Aufl. Leipzig 1936. 117 s

\section{Puutarhanhoito.}

B a cher, T., \& Soren se n; F., Dyrkning af Kokkenurter paa Friland og under Glas. Kbhvn 1943. $502 \mathrm{~s}$.

B a u e r, W., Hela året $i$ min trädgård. Tips för prydnadstäppan. Sthlm 1942. $146 \mathrm{~s}$.

B e r g e, G., Hemträdgården, dess anläggning och skötsel. 7. uppl. Sthlm 1943. 208 s.

D a h 1, C. G., Beskärning av fruktträd, bär-och nötbuskar. 6. uppl. Sthlm 1944. $99 \mathrm{~s}$.

Fruktträ gården. Uppsatser utg. av Nylands fruktodlarförening. II-V. Hfors 1931- 45 .

[F y r t i o] 40 år för svensk trädgårdsodling. S.H.T.F. 1903-1945. Sveriges handelsträdgårdsmästareförbunds jubileumsskrift jämte årsbok 1942. Red. av G. Ledin. Motala 1943. $369 \mathrm{~s}$.

Graida, V. P., Z urbickij, Z. I., \& Pestova, M. N., Ovošči v otkrytom grunte. Moskva 1944, $72 \mathrm{~s}$.

H j e rn, T., Häckar, deras anläggande och skötsel. Sthlm 1937. 119 s.

- J-_ Jordberedning och sådd. Sthlm 1938. $78 \mathrm{~s}$.

- Rosor. Sthlm 1937. $179 \mathrm{~s}$.

J o h a n s s on, E., Besprutning av fruktträd och bärbuskar. 11. uppl. Sthlm 1944. $62 \mathrm{~s}$.

- i- Gödsling av fruktträd och bärbuskar. 2. uppl. Sthlm 1945. $43 \mathrm{~s}$.

L e h to ne n, V., Puutarhakirja. 5. pain. Porvoo 1945. $213 \mathrm{~s}$.

L u n d i n, Y., Hemträdgårdens frukter och bär. Göteborg 1944. 133 s.

L u o s t a ri n e n, Ka t r i, Kukkiva pihamaa ja tuottoisa kasvitarha. Hki 1945. 16 s. Nils so n, E., Baljväxter, gurkor och tomater. 2. uppl. Sthlm 1943. $123 \mathrm{~s}$. 
Paluda n, H. K., \& B a cher, T. (Rəd.), Blomsterdyrkning under Glas. De vigtigste Handelskulturer. Kbhvn 1944. 534 s.

Praksin, S., \& S a m orukov, P., Rabočij ogorod. 3. izd. Moskva 1944. $100 \mathrm{~s}$.

Salonen, F., Kotipuutarhurin opas. 3. pain. Porvoo 1945. $128 \mathrm{~s}$.

- $\ldots$ \& $\mathrm{H}$ a a p a n e n, A., Kotipuutarhurin tietokirja. Aakkosellinen hakuteos. Hki 1945, $419 \mathrm{~s}$.

- \& \& J a a tine n, K., Kodin puutarha. 5. pain. Porvoo 1945. 488 s.

Söd erberg, E., Växterna i stenpartiet. Sthlm 1939. $96 \mathrm{~s}$.

Trolle, Els a a f, Kryddgården. Sthlm. 1940. 118 s.

Z a ostrovska ja, E. N., Ustroistvo chranilišč i chranenie v nich ovoščej i plodov. Moskva 1944. $66 \mathrm{~s}$.

\section{Maatalouskoneet ja -välineet.}

B erglund, N., \& A ndersson, Y., Lantbruksmaskiner och redskap. Sthlm 1945. $347 \mathrm{~s}$.

En š, A. F., \& D o ga n ovski, M. G., Sel'skochozajstvennye mašiny i orudija. Moskva 1944. 224 s.

Grön é, L., Svensk standard för direktdrivningen från traktor till arbetsmaskin. Uppsala 1944. 11 s. (Särtr. fr. Jordbrukstekn. föreningen, N. 55.)

Pero, P., Maatalouspolttomoottorit ja traktorit, niiden käyttö ja hoito. 2. pain. Hki 1945. 222 s.

S ip i lä, M., Jäiden sahaus- ja nostotöistä. Hki 1945. 11 s. (Erip.: Työtehoseuran vuosik. 1945.)

- Rekien standardisoimisesta. Hki 1945. 15 s. (Erip.: Työtehoseuran vuosik. 1945.)

Skördetröskn ing. Eskilstuna 1944. $51 \mathrm{~s}$.

\section{Maatalousrakennukset.}

A n d e rs s o n, Y., Byggandet av silor och ensileringsarbetets mekanisering. Uppsala 1944. 12 s. (Särtr. fr. Jordbrukstekn. föreningen, N. 58.)

- - Impregnering av träsilor med arsenik- och kopparhaltiga impregneringsmedel. Uppsala 1944. 4 s. (Särtr. fr. Jordbrukstekn. föreningen, N. 56.)

- Tornsilor av trä. Uppsala 1944. 14 s. (Särtr. fr. Jordbrukstekn. föreningen, N. 54.)

Byggekonsulenten. Raadgiver i Landbrugets Byggesporgsmaal. Under Red. af W. Kernel \& H. Ærsoe. Frederiksberg 1944. 255 s.

Gustafsson, Y. \& Gertrud, Talousvesi. Suom. Hki 1945. 62 s.

Si k o n en, H., Pienviljelijän rakennusoppi. Avust. U. Ảberg \& V. A. Arola. 2. pain. Hki 1941. 229, $7 \mathrm{~s}$.

S i pilä, M., Maatalousrakennusten sijoitus ja sisustaminen lisäämään työtehoa ja työn iloa. Hki 1945. 3 s. (Erip.: Työtehoseuran vuosik. 1945.)

U ts tälln ing en Bo bättre. Göteborg 1945. $112 \mathrm{~s}$.

\section{Karjanhoito ja maitotalous.}

A n n i la, M., Karjatalous tuottavammaksi. Hki 1944. 20 s. (Erip.: Pellervo 1943 22.) Nautakarjatalouden kannattavuudesta eräillä tiloilla tarkastuskirjanpitovuonna 1941-42. Forssa 1943. Ss. 83-87. (Erip.: Maatalous 1943:4.) 
Axelsson, J., \& Olsson, N., Mineralämnen och vitaminer i husdjurens utfodring. Sthlm 1944. $32 \mathrm{~s}$.

B e le n'kij, N. G., Stolbnjak u lošadej i mery bor'by s nim. Moskva 1944. 208 s. B r ü n in g, J., Koiran kasvatus ja opetus. Hlinna 1945. 222 s.

Fabritius, L. J., Hevoskasvatusyhdistys Hippos 50-vuotias. Kertomus toimintakaudelta 1894-1944. Turku 1945. $80 \mathrm{~s}$.

— - Hästavelsföreningen Hippos 50 år. Redogörelse för verksamheten 1894-1944. Åbo $1945.79 \mathrm{~s}$.

F ör te c kn i n g över pälsdjurslitteratur. Red. av I. Johansson. Malmö 1945. $50 \mathrm{~s}$. (Särtr.: Svensk pälsdjurs- o. skinnkalender.)

Garner, Frank H., The cattle of Britain. New impr. London 1945. 158 s.

Gusta v so n, K. H., Läder, dess kemi, tillverkning och egenskaper. Sthlm 1944. $291 \mathrm{~s}$.

H a n d ledn ing i klassificering av kött. Under red. av B. Stensiö. Sthlm 1945. $175 \mathrm{~s}$

H a r m i a, A., Husdjurens förädling. Övers. Åbo 1944. $192 \mathrm{~s}$.

Helve, Y., Mitä agronomin on tiedettävä turkiseläinten kasvatuksesta. Hki 1945. $23 \mathrm{~s}$.

H usdjurslära för de lägre lantbruksläroverken. 7. uppl. II. Larsson, S., Husdjurens utfodring och vård. Sthlm 1945. $348 \mathrm{~s}$.

H ä s te n. Praktisk handbok i hästavel och hästuppfödning. Utarb. av H. Stjernswärd, G. Liedberg, E. Cassel ... 4. uppl. Sthlm 1945. 258 s.

In k ov a a ra, N., Kannattava lammastalous. 2. pain. Hhi 1945. 128 s.

—- — Vuohi — jokaisen lehmä. Hki 1945. $52 \mathrm{~s}$.

It ä-S u o m en karjan kantakirja. 41. Kuopio 1945. XXXVII, 178 s.

I v a n ov, M. F., Sočinenija. I. Trudy po ovcevodstvu. Moskva 1939. $602 \mathrm{~s}$

J e n s e n, H. M., Mejeribrugets Mikrobiologi. 3. Opl. Odense 1941. $175 \mathrm{~s}$.

J o h n s s o n, R., Räkenskapstabeller för kontrollassistenter. Sthlm 1945.159 s.

K a ja n oja, P., Karjataloutemme nousua kohden! Hki 1943. 16 s.

$\mathrm{K}$ a skimies, E., Tuottava mehiläishoito. Hki 1945. $70 \mathrm{~s}$.

K il a n d e r, S., Zur Kenntnis der schwedischen Landschweine. Sthlm 1943. 17 s.

(Arkiv för zoologi $34 \mathrm{~A}, \mathrm{~N}$. 17.)

Kra snov, K. A., Vydelka šubnoj ovčiny. 2. izd. Moskva 1943. 23 s.

K u u rma, E. K., Kääntöpesä. Käytännöllinen mehiläispesä, sen rakenne ja käyttö. Hki 1945. 14 s. (Siipikarjanhoit.liiton mehiläishoid. julk. 2.

L a g e r löf, N., Husdjurens vanligaste sjukdomar. Sthlm 1943. $295 \mathrm{~s}$.

L u n d, A., Pelsdyravl i Danmark. 2. Udg. Kbhvn 1944. $191 \mathrm{~s}$.

Län si-S u o men karjan kantakirja. 29. Vammala 1945. CVIII, $400 \mathrm{~s}$.

M e n'š o v, B. G., Razvedenie krolikov i ulučšenie ich porod. Moskva 1943. $72 \mathrm{~s}$.

M u stonen, M., Taloussika. Hki 1945. $47 \mathrm{~s}$.

$\longrightarrow$ — \& H e lve, Y., Kaniini. 8. laaj. pain. Hki 1945. $125 \mathrm{~s}$.

Nils so n, J., \& Ryde, H., Husdjurskontroll. Sthlm 1939. $123 \mathrm{~s}$.

———— \& Ör b o r n, A., Mjölken och dess behandling. 3. uppl. Sthlm 1945. $119 \mathrm{~s}$.

Novikov, E. M., Planirovanie mechovogo proizvodstva. Moskva 1941. $292 \mathrm{~s}$ Ny l a nder, H., Caj a n d e r, E., Poi järvi, I., \& T e rho, T., Nötboskapsskötsel. Övers, 7. omarb.uppl. Hfors 1945. $350 \mathrm{~s}$. (Svenska lantbrukssällsk. i Finl. förbund, N. 114.) 
Nørlund, A. P., Hunde-Avl og Opdræt. Kbhvn 1939. $46 \mathrm{~s}$.

Orlow-A n d erse n, G. O., Rigtig Forspænding og Kørsel. Kbhvn 1944. 32 s.

Ot to s e n, H. E., Undersøgelser over Corynebacterium Magnusson-Holth. (Diss.) Kbhvn 1945. 119 s.

P a 1 kin, G. A., Razvedenie i soderžanie krolikov. Moskva 1944. 63 s.

Pa loheimo, L., Karjatalouden osuus taistelussa keuhkotautia vastaan. Hki 1944. 4 s. (Erip.: Karjatalous 1944: 23.)

- "- Mitä tarkoitetaan eläimen nettopainolla? Hki 1944. 3 s. (Karjatalous 1944: 21.)

_- Naudan painonmenetyksestä matkalla teurastamoon. Hki 1944. 4 s. (Erip.: Pellervo 1944: 21.)

—- Perunat ja perunankuoret syötettävä kaniineille keitettyinä. Hki 1944. 1 s. (Erip.: Turkistalous 1944: 9.)

—- Rasvan sijoittumisesta lypsylehmän ruumiissa. Hki 1945. 4 s. (Erip.: Karjatalous 1944: $25-26$.)

$\longrightarrow$ - Rehuanalyysin uudistamisesta. Forssa 1944. Ss. 212-215. (Erip.: Maatalous 1944: 12.)

Sa charov, P. P., Profilaktika i lečenie zaraznych boleznej krolikov. Moskva 1944. $48 \mathrm{~s}$.

S a n d e li n, A. E., Maitotaloustuotteiden tutkiminen. 3. uus. pain. Hki 1945. $194 \mathrm{~s}$.

-1)- Voinvalmistus. 2. uus. pain. Hki 1945. $318 \mathrm{~s}$

Skrebitski j, G., Vychuchol’. Moskva 1945. 52 s.

S metnev, S. I., Upravlenie produktivnost'ju kur metodom kruglogodovogo komplektovanija stada. Moskva 1944. $56 \mathrm{~s}$.

S p e r a n s k i j, V., Peredovaja ferma krupnogo rogatogo skota kostromskoi porody. Moskva 1945. $88 \mathrm{~s}$

S t a a f-B u s c h, D a g n y, Kristidskritter och fjäderfän. Hfors 1945. 163 s.

Starkov, I. D., Razvitie serebristo-černych lisic. Moskva 1940. $96 \mathrm{~s}$.

$\mathrm{S}$ t o r g å r d s, T., Hapatinmaidon valinnasta ja siinä huomioon otettavista seikoista. Hki 1944. 9 s. (Erip.: Karjantuote 1944: 20.)

—- Hur tillverkas ett aromrikt smör? Hfors 1943. 8 s. (Särtr.: Lantmannabladet 1943: 50.)

—- I vilken grad är järn- och kopparhalten avgörande för smörets hållbarhet? Arlöv 1945. 4 s. (Särtr.: Svenska mejeritidn. 1945: 8.)

—- Kuoritunmaidonjuustojen kokoomus ja kypsyminen. Hki 1945. Ss. 487-493. (Erip.: Karjantuote 1945: 20)

- - Meijerien liiketilaston uudistaminen. Hki 1944. 12 s. (Erip.: Karjantuote 1944: $12-13$.)

—- Mistä aiheutuvat hapatinhäiriöt? Hki 1944. 10 s. (Erip.: Karjantuote 1944: 19.)

$\longrightarrow$ - Oxidationsfelen i smör. Arlöv 1945. 8 s. (Särtr.: Svenska mejeritidn. 1945; 41-42.)

- - Rauta- ja kuparipitoisuuden vaikutuksesta voin kestävyyteen. Hki 1945. 8 s. (Erip.: Karjantuote 1945: 1-2.)

—- Voin peroksidiluku. Hki 1944. 10 s. (Erip.: Karjantuote 1944: 16.)

$\rightarrow-$ Voinvalmistuksen tekniikka uudenaikaisia metallikirnuja käytettäessä. Hki 1941. 8 s. (Erip.: Karjantuote 1941: 16.)

T u o m a n e n, L., Mehiläisten hoito. Porvoo 1945. 307 s.

W a t s o n, S. J., Silage and crop preservation. London 1938. $192 \mathrm{~s}$. 
We is s berg, I. E., Pamjatka mezdril’ščiku. Moskva 1944. 24 s.

Virtan en, A. I., AIV-systemet såsom grundval för husdjurens utfodring. Sthlm 1945. $304 \mathrm{~s}$

Voh 1 on e n, Ma i ja, Nykyaikainen lammastalous, 4. pain. Porvoo 1945. $116 \mathrm{~s}$

\section{Maanviljelystalous ja maatalouspolitiikka.}

A g e r, H., Arbetsstudieorganisation och -utrustning. 2. uppl. Sthlm 1944. 86 s. A i l a s, T., Pellervon maatalouskirjanpidon opas, 2. pain. Hki 1945. $64 \mathrm{~s}$

A jo, R., Tampereen liikennealue. Hki 1944. XIV, 352 s. (Kansantaloud. tutkim. XIII.)

A 11 wood, M. S., \& $\mathrm{R}$ a n e mark, In ga-Britt, Medelby. En sociologisk studie. Sthlm 1943. $358 \mathrm{~s}$.

A s u t u skysy m y ks iä. Pihkala, R., Maakysymyksen ratkaisu. Kivinen, E., Tietoja viljelyskelpoisen maan levinneisyydestä maassamme, ym. Hki 1945. $16 \mathrm{~s}$.

De norrländska hemmamarknadsindustriernas transportkostnader. Sthlm 1944. 122 s. (Industriens utredningsinstitut. Norrlandsutredningen.)

E 11 i lä, K. J., \& L e h t in e n, A., Realiobligatiot ja siirtoväen korvauskysymys. Hki 1944, $21 \mathrm{~s}$

Gu 11 a n d e r, A., Bönderna vakna. 2. uppl. Sthlm 1942. $255 \mathrm{~s}$.

H e ik kilä, M., Jä n n es, J., \& K u 11 be r g, H., V. 1944 asutuskomitean mietintöjen arvestelua. Hki 1945. $15 \mathrm{~s}$

H e i n ä m i es, V., (toim.), Maanomistusolojemme uudistus. Maanhankintalaki ja siihen liittyvä lainsäädäntö. Hki 1945. $158 \mathrm{~s}$.

$\mathrm{H}$ in $\mathrm{n}$ a s to korvauslakien mukaan korvattavan irtaimiston arvioimista varten. Hki 1945. $56 \mathrm{~s}$.

H o $1 \mathrm{ma}$, K., Maaltapako, maataloustyön tuottavuus ja asutuskysymys. Hki 1945. 7 s. (Ylip.: Maaseudun Tulevaisuus 1945: 1.)

H y vön e n, V., 40 vuotta osuuskassatoimintaa. Hki 1945. $126 \mathrm{~s}$.

J o n s s o n, J. N., Jorden, bönderna och samhället. Sthlm ‘1943. $150 \mathrm{~s}$

J ä n n es, J., Hallituksen maanhankintalakiesitys. Hki 1945. 12 s.

K a i t i l a, E., Kustannusten riippuvaisuus suoritemäärästä. I. (Diss.) Hki 1945. 208s. Kansa la iskirja. Toim. I. Laati. Tammisaari 1944. $212 \mathrm{~s}$.

K e y n es, J. M., Sysselsättningsproblemet. Allmän teori för produktion, ränta och pengar. Övers. Sthlm 1945. $414 \mathrm{~s}$.

K ivia lho, K., Kansantalouden oppikirja, 4. pain. Porvoo 1945. $209 \mathrm{~s}$

K o m it e a $\mathrm{nm}$ i e t in tö 1943: 6. Asutuslainsäädäntötoimikunnan mietintö. I. Hki 1943. $304 \mathrm{~s}$.

L e iviskä, I., Raaka-aineet, niiden alueellinen jakautuminen ja tuotanto. Hki 1944. $364 \mathrm{~s}$

M y r d 1, A lva, Folk och familj. Sthlm 1944. $496 \mathrm{~s}$.

M ä ki, A. Laskelmia viljelysmaan pakkolunastuksen vaikutuksesta pääoma-, työja verokustannuksiin Koskelan tilalla. Hki 1945. $39 \mathrm{~s}$.

- $\rightarrow$ - Rehujen jalostusarvolaskelmista. Hki 1945. Ss. 44-66. (Ylip.: Maataloustiet. aikakausk. 1945: 3 .)

- - Viljelysmaan pakkolunastuksen vaikutuksesta luovuttavan viljelmän maatalouteen ja sen kannattavaisuuteen. Hlinna 1945. 59 s. (Erip.: Suomen maataloustiet.seuran julk. 58.) 
N or d i n, J., Lantarbetstidslagen den 18 juli 1942. Uppsala 1942. $45 \mathrm{~s}$.

Pelto n e n, U., Työntutkimukset teollisuudessa. Porvoo 1944. $101 \mathrm{~s}$.

Pernu, A une, Maidon ja maitotaloustuotteiden tuotannon ja käytön arviointia. Paljonko maitotaloustuotteita on kulkenut salakaupassa? Hki 1943. 7 s. (Erip.: Suomen osuustoimintalehti 1943: 3.)

Pihkala, K. U., Laskelmia maanviljelyksen taloudellisista edellytyksistä sotavuosina. Hki 1945. Ss. 79-100. (Erip.: Maataloustiet. aikakausk. 1945: 3.)

- - Tutkielma maatalouden kokonaistuoton ja liikekustannusten suhteesta ennen sotaa ja sodan aikana. Hki 1943. $34 \mathrm{~s}$.

- )- Työvoiman käyttö ja maataloustyön tuottavuus erisuurvisilla viljelmillä. Forssa 1945. Ss. 34-38. (Erip.: Maatalous 1945: 2.)

Pih k a la, R., Nykyhetken maakysymyksen ratkaisu Suomessa. Hki 1945. 18 s. (Ylip.: Kansantaloud. aikakausk. 1945: 1.)

$\longrightarrow$ - Siirtoväen asutuskysymys. Hki 1940. 28 s.

Rationaliseringsproblem inom jordbruket. Sthlm 1945. $174 \mathrm{~s}$.

Silverstolpe, G. W., En krönikebok. Den svenska konsumentkooperationens väg. Sthlm 1944. $246 \mathrm{~s}$.

Si m on en, S., Maatalouden vallankumous. Maatalouspolitiikkaa ennen ja nyt. Porvoo 1945. $392 \mathrm{~s}$.

S i pilä, M., Maa-, metsä- ja kotitaloustyön tutkimustarpeista. Hki 1945. 3 s. (Erip.: Työtehoseuran vuosik. 1945.)

Valtiovarainministeriön ohjeita arvioimislautakunnille. I. Toisen korvauslain yleistä soveltamista ja tulkintaa koskevat ohjeet. II. Rakennusvahinkojen arvioimisperusteet. III. Maatalousvahinkojen arvioimisperusteet. IV. Metsätalousvahinkojen arvioimisperusteet. Hki 1945.

V i is i vuotta kansanhuoltoa. Julk. Kansanhuoltoministeriö. Toim. U. U trio. Hki 1945. $196 \mathrm{~s}$.

W ill a n d t, O. W., Pienviljelijäin taloudellinen asema. Hki 1941. $24 \mathrm{~s}$.

(Erip.: Suomen osuustoimintalehti 1941: 6-7, 10-11.)

$\mathrm{Z}$ is chka, A., 5000 Jahre Kleidersorgen. Leipzig 1944. 374 s.

\section{Kotitalous ja elintarvekysymys.}

A n d e r s e n, E $1 \mathrm{n}$ a R e g n e r, I stället för kött. Övers. Sthlm 1944. $66 \mathrm{~s}$.

B e tæn kning om Oprettelsen af en videnskabelig Hushıldningshøjskole i Tilknytning til Aarhus Universitet. Aarbus 1942. $32 \mathrm{~s}$.

Borgström, S., Studien über den nahrungsphysiologischen Wert der Weizenkleie unter besonderer Berücksichtigung der Bedeutung der Erhitzung. (Diss.)

Lund 1941. $128 \mathrm{~s}$.

D a h l, E ls e, Svensk frukt och svenska bär i daglig kost. Sthlm 1940. $72 \mathrm{~s}$.

E g e, R., Rationel Kost og Rationeringen. Kbhvn 1941. $152 \mathrm{~s}$.

F a h l a n d e r, A., Varukännedom för textilhandeln. Sthlm 1944. $218 \mathrm{~s}$.

F e hr, L o u is e, Garn och vävnader. 2. uppl. Sthlm 1944. $60 \mathrm{~s}$.

Gebhard, Maiju, Toimenpiteistä vaatteiden pesutyön järkiperäistämiseksi. Vammala 1943. 11 s. (Erip.: Työtehoseuran vuosik. 1943.)

— - - Veden kantaminen käsivarassa, kahlulla ja ämmänlängillä. Vammala 1943. 4 s. (Erip.: Työtehoseuran vuosik. 1943.) 
Gebhard, Maiju, Vedforslingen inom hemhushållningen bör rationaliseras. Hfors 1945. 4 s. (Särtr.: Husmodern 1945: 2.)

Groth-P e terse n, E., Grundlag for Beregning af Kostens Næringsværdi. Kbhvn 1940. $90 \mathrm{~s}$.

$\mathrm{H}$ a n d bo k för textilmannen. Göteborg 1945. $124 \mathrm{~s}$.

$\mathrm{H}$ a n d l e d n ing i näringskemi för kurser i huslig ekonomi. [Kompendium utg. av Edith Klarin.] Sthlm 1941. $106 \mathrm{~s}$.

He mslöjdens märkbok. Sthlm 1944. 17 pl.

H in tikka, T. J., \& S a in i o, A., Sienikirja ruokasienien kerääjille. Hki 1942. $178 \mathrm{~s}$

H y l a n d e r, H., Grunderna för fläckurtagning. Sthlm 1945. $120 \mathrm{~s}$.

J e a n s s o n, A 1 i c e, Vardagens ekonomi. Sthlm 1942. $218 \mathrm{~s}$.

K a s t m a n, G r e t a (utg.), Hemvårdslära. Sthlm 1942. $148 \mathrm{~s}$.

K e y, K e r s t i n, Hemvård. 3. uppl. Sthlm 1941. $179 \mathrm{~s}$.

Kitunen, E11a, Ravintoaineoppi. Hki 1945. $40 \mathrm{~s}$.

-.) — \& Tarkkala, L a in a, Työnmenekki ruokaleivän valmistuksessa maalaistalossa. Hki 1945. 33 s. (Erip.: Työtehoseuran vuosik. 1945.)

Kontturi, Hulda, Luonnonväreillä värjäämisestä. 2. pain. Hki 1945. 48 s.

Krasinskij, N. P., Rukovodstvo po sboru, suške, chraneniju i pererabotke možževelovoj jagody na konditerskie izdelija i napitki. Kaluga 1943. 24 s.

Larsson, Beda, Hemfärgning med växtämnen. 7. uppl. Sthlm 1944. $80 \mathrm{~s}$.

L u n h, H., Fackskolan för huslig ekonomi i Uppsala 1895-1945. En minnesskrift. Uppsala 1945. $307 \mathrm{~s}$.

M o n te 11, A i n a. Fruktkonserver för vardagsbehovet. 4. uppl. Sthlm 1942. $25 \mathrm{~s}$.

Mönsterbla d. Utg. av Föreningen för svensk hemslöjd. Kartong $1-3$. Sthlm 1944 .

N o g l e tilberedte Fødemidlers Næringsværdi. Utg. af Statens Husholdningsraad. Kbhvn 1943. $30 \mathrm{~s}$.

N ordl u nd, Greta, Ekonomisk hemtvätt. Sthlm 1945. $27 \mathrm{~s}$.

O d i n, M., Vitaminer och vitaminbristsjukdomar. Sthlm 1945. $266 \mathrm{~s}$.

O l ki, M a ry, Kirjokintaita ja muita kansanomaisia neuletöitä. 2. pain. Porvoo 1944. $83 \mathrm{~s}$.

Rå d och anvisningar angående maskintvättning av bomulls- och linnevävnader med eller utan cellullinblandning. Sthlm 1942. 19 s. (Föreningen Rationell textiltvätt vid Ingeniörsakademien. Meddel. 9.)

S a i n i o, A., Tekstausopas. Hki 1944. $40 \mathrm{~s}$.

$\mathrm{S} \mathrm{chn}$ eidmann, L. O., Proizvodstvo koncentratov vitamina $\mathrm{C}$ iz rastitel'nogo syr'ja. Kaluga 1944. $124 \mathrm{~s}$.

S k a d or på tvättkläder, hur de uppstå och förhindras. Sthlm 1945. $32 \mathrm{~s}$.

Skeri-Mattsson, Anna, \& Osvald, Ingrid, I vävstolen. I-II. Sthlm 1942-44. $170+176 \mathrm{~s}$.

Ta lvitie, A., Pesuaineista ja niiden valmistuksesta. 2. pain. Hki $1945.16 \mathrm{~s}$. (Kemian keskusliiton julk. 5.)

Utri o, U. (toim.), Pois pula ja puutteet. 3. pain. Hki 1943. $192 \mathrm{~s}$.

V a r u lexikon. Livsmedel. Sthlm 1944. $430 \mathrm{~s}$.

Virg i n, E b b a, Vad finns $\mathrm{i}$ vår mat? Sthlm 1945. $28 \mathrm{~s}$. 


\section{Metsätalous.}

Erkkjlä, E. E., Kotitalouspuun käyttö. [Hki 1945. 32 s.

K a le la, E. K., Metsät ja metsien hoito. Porvoo 1945. 368 s.

K a 11 i o, K., Haapa, sen kasvatus ja tuoton lisääminen. Hki 1945. 88 s.

P o h j a ka 11 i o, A., Metsänhoito-opas. Hki 1945. $72 \mathrm{~s}$.

S u o m e n metsäkirjallisuutta v. 1941-1942. Lisäyksià julkaisuun "Bibliographia forestalis». Hki 1945. $17+16 \mathrm{~s}$.

Virtanen, A. I., \& Koistinen, O. A., Puun selluloosan ja pentosaanien käyminen. Hki 1945. $11 \mathrm{~s}$. (Kemian keskusliiton julk. 7.)

\section{Metsästys ja kalastus.}

$\mathrm{H}$ a $1 \mathrm{~m} \mathrm{e}$, E., Planktologische Untersuchungen in der Pojo-Bucht und angrenzenden Gewässern. I. (Diss.) Hki 1944. X, $180 \mathrm{~s}$.

Y länne, Y., Metsästäjän käsikirja. 3. pain. Hki 1945. $472 \mathrm{~s}$.

\section{Luonnontieteet. Matematiikka.}

B l a c h e r, L. J., Kurs obščej biologii s zoologiej i parazitologiej. Dlja medicinskich institutov. 4. izd. Moskva 1944. $484 \mathrm{~s}$.

B onn ier, G., \& Tedin, O., Biologisk variationsanalys. Sthlm 1940. $325 \mathrm{~s}$.

D a h 1 be r g, G., Perinnöllisyys ja rotu. Suom. Hki 1944. $192 \mathrm{~s}$.

F a g e r lind, F., Die Samenbildung und die Zytologie bei agamospermischen und sexuellen Arten von Elatostema... Sthlm 1944. $130 \mathrm{~s}$.

$\mathrm{H}$ a a rtman, L. v., Zur Biologie der Wasser- und Ufervögel im Schärenmeer Südwest-Finnlands. (Diss.) Hfors 1945. $120 \mathrm{~s}$.

Hi itonen, I., \& Poijärvi, A., Koulu- ja retkeilykasvio. 4. pain. Hki 1944. $407 \mathrm{~s}$.

Hof sten, E. v., Praktisk statistik. Sthlm 1942. $154 \mathrm{~s}$.

H ortling, I., Pieni lintukirja. I. Hki 1944. $62 \mathrm{~s}$.

Kivirik k o, K. E., Koulun kasvioppi. 18. pain. Porvoo 1945. 274 s.

Leht on en, L., Lintuparatiisi pääkaupungin liepeillä. Vanhankaupunginlahti ja sen linnusto. Porvoo 1945. $180 \mathrm{~s}$.

Listo, J., Kasvioppi alempia maatalouskouluja varten. 3. pain. Porvoo 1945. $104 \mathrm{~s}$.

—- Laskuoppi maamieskouluja, karjanhoitokouluja ja kansanopistoja varten. 3. pain. Porvoo 1945. $148 \mathrm{~s}$.

P a a vo la, M., Sähkötekniikan oppikirja. 3. pain. Porvoo 1944. $380 \mathrm{~s}$.

Pu 1 k k in e n, A., Kasvioppi. 8. pain. Porvoo 1945. $400 \mathrm{~s}$.

R o s s i, V., Lyhyt lentäjän sääoppi. Hki 1944. $124 \mathrm{~s}$.

Vartiova ra, U., Mikrobiologian peruskurssin luentoja. Hki $1945.116 \mathrm{~s}$. (Monist.)

W in g e, Ø., Arvelighedslære paa eksperimentelt og cytologisk Grundlag. 3. Udg. Kbhvn 1945. $489 \mathrm{~s}$.

Virta n en, A. I., Valkuaisaineet elämän keskeisinä aineina ja kemiallisen tutkimuksen kohteina. Hki 1945. $22 \mathrm{~s}$. 


\section{Sarjat.}

Kotimaiset.

A gronom i en yhdistyksen julkaisuja. 41. Agronomien yhdistyksen vuosikertomus. 1943-44. Hki 1945. 104 s.

E t e lä-P o h j a m a a m manviljelysseuran vuosikirja. 81. 1943. Vaasa 1945. $130 \mathrm{~s}$.

Fin la n d s natur. 2-4. Naturskyddsföreningens i Finland årsbok. 1942-44. Hfors $1942-45.40+40+40 \mathrm{~s}$.

F i n s k a hushållningssällskapets årsbok. 1944. Åbo 1945. 56 s.

F i n s k a mosskulturföreningens årsbok. 1943. Hfors 1945. $128 \mathrm{~s}$.

F år s köts e ln. [Utg. av] Får- och getavelsföreningen. 1945: 1. Vammala 1945. $60 \mathrm{~s}$.

H ä m e e n läänin maanviljelysseuran vuosikirja. 50-51. 1943-44. Hlinna 1944 45. $96+90 \mathrm{~s}$.

$\mathrm{H}$ ä m e e n-S a t a k u n a n maanviljelysseuran kirjanpitotoimiston julkaisuja. 4. Virtane n, K. L., Maatilojen kannattavuus... 1926-40. Tampere 1945. $175 \mathrm{~s}$.

— maanviljelysseuran vuosikirja. 35. 1944. Kangasala 1945. $113 \mathrm{~s}$.

[I t ä-S u o m e n karjanjalostusyhdistyksen] ISK:n tiedonantoja. 82-83. Kuopio 1945. $72+48 \mathrm{~s}$.

$\mathrm{K}$ a j a a n in maanviljelysseuran vuosikirja. 1943-44. Kajaani 1944-45. $124+$ $122 \mathrm{~s}$.

K e r to m u s Hämeenläänin meijeriliiton toiminnasta. 1943-44. Kangasala 1945. $79 \mathrm{~s}$.

K e r t o m u s karjanjalostusyhdistys ISK:n toiminnasta. 1943-44. Kuopio 1944 1945. $39+36 \mathrm{~s}$.

K e r t o m u s Keski-Pohjanmaan meijeriliiton toiminnasta. 1944. Raahe 1945. $32 \mathrm{~s}$.

K e r to m u Savo-Karjalan meijeriliiton toiminnasta. 26-27. 1943-44. Mikkeli $1944-45.46+51 \mathrm{~s}$.

K e s k i-P o h j a n m a n maanviljelysseuran vuosikirja. 36. 1944. Kokkola 1945. $94 \mathrm{~s}$.

K e s ki-S u o m e n maanviljelysseuran vuosikirja. 51. 1944. Jkylä 1945.95 s.

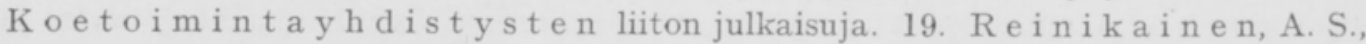
\& Li n kol a, O., Viljelysmaan pinta-alan selvittämisestä. Hki 1944. 79 s.

K u o pion maanviljelysseuran vuosikirja. 84. 1944. Kuopio 1945. $120 \mathrm{~s}$.

La n t b r k k min is teriet. Produktionsavdelningen. Flygblad. 37-38. Hfors 1945. $2+7 \mathrm{~s}$.

M a a ki in teistöpa n k ki. Vuosikertomus. 1944. Hki 1945. $8 \mathrm{~s}$.

Ma a n viljelysinsinööriy distyksen vuosikirja. 1942-1943. Hki 1943. $122 \mathrm{~s}$.

Ma a taloushallituksen tiedonantoja. $285-288,290$. Hki $1944-45$. 285-286. Valtion maanviljelyskemiallisen laboratorion tiedonantoja. $20-21$. 1942. $14+21 \mathrm{~s}$.

287. Valtion siementarkastuslaitos, 24. 1942-43. $22 \mathrm{~s}$.

288. Tutkimuksia Suomen maatalouden kannattavaisuudesta.. 26, 27. 1937/39. $132 \mathrm{~s}$.

290. Valtion maanviljelyskemiallisen laboratorion tiedonantoja. 22. 1943. $26 \mathrm{~s}$. 
Ma a ta lou s min is teriön asutusasiainosaston julkaisuja. 7-9. Hki 1945.

7. Maanhankintalaki. $293 \mathrm{~s}$.

8. Esitelmiä, jotka pidettiin maanlunastuslautakuntien ... neuvottelupäivillä. $115 \mathrm{~s}$.

9. E r k i ö, V., Asutusmaan hinnoista vuosina 1937-1938. 6 s.

$\rightarrow-$ asutusasiainosaston rakennustoimiston julkaisuja. 1-3. Vammala 1945. 28+ $38+66 \mathrm{~s}$.

$\longrightarrow$ - tuotanto-osasto. Lehtinen $37-38$. Hki 1945. $2+7 \mathrm{~s}$.

M a a t a 1 o us e u rojen keskusliiton julkaisuja. 345-346. Hki 1945.

345. Maatalousseurojen keskusliiton 26. edustajakokous 1945 . Pöytåkirja. $33 \mathrm{~s}$. 346. Maanviljelysseurojen toiminta. 1943. $125 \mathrm{~s}$.

Ma ataloustuot tajain keskusliiton julkaisuja. 54-55. Vuosikertomus 1943-44. $109+85 \mathrm{~s}$.

—)- keskusliiton metsävaltuuskunta ja sen toiminta. 1944. Hki 1945. 25 s.

Marttaliton vuosikertomus. 1943. Hki 1944. $61 \mathrm{~s}$.

Mikkelin lään in maanviljelysseuran vuosikirja. 83. 1944. Mikkeli 1945. $72 \mathrm{~s}$. Osu uskas ojen Keskus Oy (OKO). Vuosikertomus. 1944. Hki 1945. 12 s. O u l v n läänin talousseuran vuosikirja. 116. 1943. Oulu 1941. $128 \mathrm{~s}$.

Pohjois-Karja la n maanviljelysseuran vuosikirja. 56. 1944 . Joensuu 1945. $119 \mathrm{~s}$.

Sian ja lostusy distyksen vuosikertomus. 1943 - 44. Kangasala 194445. $40+48$ s.

$\mathrm{Si}$ ipikarjan hoita ja in liton vuosikirja. 26. 1944. Hlinna $1945.55 \mathrm{~s}$.

$\mathrm{Sik}$. Sianjalostusyhdistyksen tiedonantoja. 79-82. Kangasala 1944-45.

S u o m e n asetuskokoelma. 1944. Hki 1944. 1778 s.

[-) - Asiarekisteri Suomen asetuskokoelmaan 1938-44. Hki 1945.

S u o m e n laiduntalous. 15-16. Laidunyhdistyksen vuosikirja. 1943-44. Vammala $1944-45.76+108 \mathrm{~s}$.

$\mathrm{S}$ u o m e n luonto. 3-4. Suomen luonnonsuojeluyhdistyksen vuosikirja. $1943-44$.

Hki $1943-45.80+96 \mathrm{~s}$.

S u o m e n maataloustieteellisen seuran julkaisuja. 56-59. Hki 1944-45.

56. 1. P a 10 h e i $\mathrm{m} \mathrm{o,} \mathrm{L.,} \mathrm{Über} \mathrm{die} \mathrm{Zusammensetzung} \mathrm{des} \mathrm{Körpers} \mathrm{der} \mathrm{Milch-}$ kühe. $63 \mathrm{~s}$.

2. Lang, E., Die Landflucht als internationale Erscheinung und ihre Bekämpfung. $18 \mathrm{~s}$.

3. Ka ja noja, P., Über die Einwirkung der Unterernährung auf die Milchproduktion der frischmelkenden Kühe. $132 \mathrm{~s}$.

57. 1. Poijärvi, I., Beiträge zur Verdauung und Verwertung von Holzzellulose beim Schwein. $53 \mathrm{~s}$.

2. S a a ri n e n, P., Lehmän veriplasman eräiden lipoidiaineosien vaikutuksesta maitorasvan muodostukseen. $131 \mathrm{~s}$.

58. 1. Mäki, A., Viljelysmaan pakkolunastuksen vaikutuksesta luovuttavan viljelmän maatalouteen ja sen kannattavaisuuteen. $59 \mathrm{~s}$.

2. W e s t e r m a r c k, N., Kasviöljyjen tuotanto taloudellisena tekijänä Suomessa. $121 \mathrm{~s}$.

59. J u u s e la, T., Untersuchungen über den Einfluss des Entwässerungsverfahrens auf den Wassergehalt des Bodens, den Bodenfrost und die Bodentemperatur. $212 \mathrm{~s}$. 
S u o m e n osuustoimintaliike. 1940. Pellervon vuosikirja. 40. Hki 1945.

S u o m e n pankki. Vuosikirja. 25. 1944. Hki 1945.

S u o m e n salaojitusyhdistys. 25. 1943. Porvoo 1944. 38 s.

$\mathrm{S}$ u o m e n suoviljelysyhdistyksen vuosikirja. $47-48.1943-44$. Hki $1944.129+$ $132 \mathrm{~s}$.

S u o m e n tilastollinen vuosikirja. Statistisk årsbok för Finland. 41. 1943. Hki 1944. XXVI, $359 \mathrm{~s}$.

$\mathrm{S}$ u o m e n virallinen tilasto. Finlands officiella statistik.

I A. Ulkomaankauppa. Vuosijulkaisu. Utrikeshandel. Arspublikation. $63-64$. 1943-44. Hki 1944-45. $359+242$ s.

- - III. Maatalous. Lanthushållning. 38: 1. Yleinen maatalouslaskenta v. 1941. Allmänna lantbruksräkningen år 1941. Hki 1945. IV, $60 \mathrm{~s}$.

—- IV. Varallisuustilastoa. Förmögenhetsförhållanden. 1940. Hki 1944. IX, $143 \mathrm{~s}$.

Svenska lantbruksproducenternas förbunds publikationer. 20. Årsbok 1944. Hfors 1945. $23 \mathrm{~s}$.

T yöt e hose u r a n julkaisuja. 34-35. Hki 1945. $32+171 \mathrm{~s}$.

Valtion maatalouskoetoiminnan julkaisuja. 124. Hki 1944.

124. J a $\mathrm{m}$ a 1 a i n e n, E. A., Über die Fusarien Finnlands. III. 24 s.

- )- maatalouskoetoiminnan tiedonantoja. 200-205. Hki 1944-45.

200. Poijärvi, I., Kokeita erilaisten selluloosalaatujen arvosta sikojen rehuna. $14 \mathrm{~s}$.

201. T a in i o, A., Niittonurmien sadoista erilaisissa viljelyskierroissa. $19 \mathrm{~s}$.

202. Poi järvi, I., Kotimaisten pellavansiemen-, unikko- ja rapsikakkujen rehuarvo. $15 \mathrm{~s}$.

203. - - Lehdekset sikojen rehuna. $9 \mathrm{~s}$.

204. H a r j a, V., Vankkuri-ohra. $12 \mathrm{~s}$.

205. P o i järvi, I., Jäkäläruokinnalla olevien porojen jäkälänkulutus syksystä kevääseen. $10 \mathrm{~s}$.

Valtion maitotalouskoelaitoksen konekoetuksia. 1-2. Jokioinen 1943-44.

1. Ruostumattoman metallikirnun, malli Kolding T. $\mathbb{E}: n$ koetuskertomus. $15 \mathrm{~s}$.

2. Spirala-pastöörin koetuskertomus. $8 \mathrm{~s}$.

A 1 a n d s försöksfält. 1944. Mariehamn 1945. 22 s.

\section{Ulkomaiset.}

B e r ät t ls e över verksamheten vid Lantbrukshögskolan med jordbruks- och husdjursförsöksanstalterna. 1943-44. Uppsala. $171 \mathrm{~s}$.

D a n m a r ks Mejeri-Statistik. 1945. Odense 1945. $151 \mathrm{~s}$.

J ordbruksforskning. Aktuella praktiska resultat. Årsbok. Utg. av Jordbrukets upplysningsnämnd. 1945. Stockholm 1945. $356 \mathrm{~s}$.

Kon tro 11 nämnden s redogörelse. 1943/44. I-IV. Malmö 1945.

L a n døkonom is k Aarbog. 46. 1945. Kbhvn 1945. XXXIV, 240 s.

L a n t brukshögskola n. Husdjursförsöksanstalten. Meddelande. 14-18. Norrtälje \& Uppsala 1943-45.

14. B en g t s s o n, S., Svinstamkontrollen 1942. $51 \mathrm{~s}$.

15. —- Produktion av späcksvin. $50 \mathrm{~s}$. 
16. J a r 1, F., Smältbarhetsförsök med kaniner. $52 \mathrm{~s}$.

17. N or dfeldt, S., J a r l, F., \& Sjöberg, K., Utfodringsförsök med kalvar och ungdjur. $46 \mathrm{~s}$.

18. O ls s o n, N., \& J a r l, F., Utfodringsförsök med betfor. $60 \mathrm{~s}$.

Lantbrukhögskolan. Husdjursförsöksanstalten. Särtryck och förhands-

meddelanden. 37-41. Norrtälje etc. $1944-45$.

37. J a r 1, F., Pälsdjurens fodermedel och utfodring. $21 \mathrm{~s}$.

38. Nordfeldt, S., Utfodringsförsök med ensilage av potatis, rotfrukter och rotfruktsblast till gödsvin. $18 \mathrm{~s}$.

39. Några preliminära uppgifter från Lantbrukshögskolans husdjursförsöksanstalts verksamhet $1943-44$. $6 \mathrm{~s}$.

40. J a r l, F., Orienterande försök med flugbekämpningsmedlet „Gesarol M». $6 \mathrm{~s}$.

41. Nordfeldt, S., Försök med A-vitaminfattigt foder till modersuggor. $18 \mathrm{~s}$.

La n t bru ks hög s k o l a n. Katalog läsåret 1944-1945. Uppsala 1945. 82 s.

M e d d e l a n d e från Jordbrukstekniska föreningen. 90-92. Uppsala 1944.

90. Årsberättelse... 1942-1943. $30 \mathrm{~s}$.

91. A ndersson, Y., \& L ön n e m a rk, H., Täckning av sädesskylar med pappershattar. $26 \mathrm{~s}$.

92. Årsberättelse ... 1943-1944. $26 \mathrm{~s}$.

M e d d e la n de från Statens forskningskommitté för lantmannabyggnader. I, 3-6. Malmö $1944-45$.

1. H j el m, L., Byggnadskapitalets och byggnadsomkostnadernas storlek vid svenska jordbruk. $90 \mathrm{~s}$.

3. A s p e, G., Nybyggnadsbehovet av bostäder för lantarbetare och innehavare av mindre jordbruk. $20 \mathrm{~s}$.

4. $\mathrm{H}$ j e $1 \mathrm{~m}$, L., Nybyggnadsverksamheten inom jordbruket under åren 1943 och 1944. $24 \mathrm{~s}$.

5. S e th, E., \& H o $1 \mathrm{~m} \mathrm{qvist,} \mathrm{N.,} \mathrm{Några} \mathrm{undersökningar} \mathrm{rörande} \mathrm{Norr-}$ landsladugårdar. $93 \mathrm{~s}$.

6. H o l m q v is t, N., Ett försök med ladugård av låghustyp. $29 \mathrm{~s}$.

M e d d e l a n d e från Statens mejeriförsök. 12-14. Malmö 1944-45.

12. Platon, B., \& S w a r t l ing, P., Undersökningar rörande karotinoch A-vitaminhalten i smör och mjölk. $118 \mathrm{~s}$.

13. Platon, B., Ö r born, A., \& T hom é, K.E., Syrning av den till utfodring använda skummjölken med ättiksyra eller myrsyra. Ss. 119-137.

14. Th o m é, K. E., Ett fall av kraftig fetthaltsdepression i mjölk i samband med kornas utsläppning på bete. Ss. 139-149.

M e d d e l a n d e från Statens trädgårdsförsök. 22-25. Malmö 1944.

22. J ohansson, E., Undersökningar rörande högkromosomiga äppleoch päronträd. $7 \mathrm{~s}$.

23. Nilsson, F., \& T o m e tor p, G., Sort- och stamförsök med köksväxter år 1943. $22 \mathrm{~s}$.

24. Ny hlé n, Å., Inverkan av spridningstiden för salpeter på avkastningen hos blomkål och vitkål. $16 \mathrm{~s}$.

25. L e n a n d e r, S. E., Resultat från sortförsök med köksväxter vid Rånna försöksstation 1938-1941. 54 s. 
M e d d e 1 a n d e n från Veterinärhögskolan i Stockholm. 14-18. 1940-44. Uppsala etc. $1939-44$.

Od l a remed de la n d e från Svenska sockerfabriks A/B. 18. Å k e r ma n, A., F r a n k, O., \& $\AA$ s t r a n d, H., Fosfatgödsling till sockerbetor. Arlöv 1945. $15 \mathrm{~s}$.

Oversigt over Regnskabsresultaterne i de danske Kontrolforeninger. 6-12. 1937-44. Slagelse 1939-45.

Prog r a m för undervisningen vid Lantbrukshögskolan. Läsåret 1944-1945. Uppsala 1944. $44 \mathrm{~s}$.

Räkenskapsresultat från svenska jordbruk. 29. Bokföringsåret 19421943. Norrtälje 1944. 120 s. (Meddel. fr. K. Lantbruksstyrelsen, N. 331.)

S o c i a 1 årsbok. Utg. av Centralförbundet för socialt arbete. 1943-1944. Stockholm 1944 .

$\mathrm{S}$ t a te n s offentliga utredningar. 1942: 43. Betänkande med förslag rörande veterinärinrättningens i Skara framtida användning m.m. Sthlm 1942. $95 \mathrm{~s}$.

—- - 1944: 26. Befolkningspolitik i utlandet. Sthlm 1944. $239 \mathrm{~s}$.

—— 1944: 35. Betänkande med förslag till lag om skyldighet för innehavare av järnväg eller spårväg att hålla stängsel. Sthlm 1944. $76 \mathrm{~s}$.

- - - 1944: 45. Betänkande med förslag till åtgärder för den jordbrukstekniska forskningens och upplysningsverksamhetens ordnande. Sthlm 1944. $75 \mathrm{~s}$.

- 1944: 56. Betänkande med förslag angående den statsunderstödda torrläggningsverksamheten. Sthlm 1944. $307 \mathrm{~s}$.

—- - 1945: 36. Utredningar angående ekonomisk efterkrigsplanering. XI: 4. Sthlm 1945. $91 \mathrm{~s}$.

Sveriges lantbruksförbund. Förvaltnings- och revisionsberättelser. 1944. Sthlm 1945. $75 \mathrm{~s}$.

—- Årsbok. 1944. Sthlm 1944. 272 s.

S veriges officiella statistik. Jordbruk med binäringar.

Arealinventeringen, kreatursräkningen och trädgårdsinventeringen den 1 juni 1943. Sthlm 1944. $113 \mathrm{~s}$.

Fiske. 1943. Sthlm 1945. $32 \mathrm{~s}$.

Jordbruk och boskapsskötsel. 1944. Sthlm 1945. $80 \mathrm{~s}$.

Årsväxten. 1944. Sthlm 1944. $23 \mathrm{~s}$.

Un dersøge ls er over Landbrugets Driftsforhold. 26-27. Regnskabsresultater fra danske Landbrug. 1941-43. Kbhvn 1944. $175+159 \mathrm{~s}$.

Växtodling. Skrifter från institutionen för växtodlingslära vid Kungl. lantbrukshögskolan. 1. A b e r g, E., Studies of crop production in the United States 1940 to 1943 . Uppsala 1944. $86 \mathrm{~s}$.

Års s k rift från Alnarps lantbruks-, mejeri- och trädgårdsinstitut. 1943. Malmö 1944. 214 s. 